REVUE DE L'INSTITUT

FRANÇAIS D'HISTOIRE

EN ALLEMAGNE

\section{Revue de l'IFHA}

Revue de l'Institut français d'histoire en Allemagne

$6 \mid 2014$

IFHA 6

\title{
Le Sonderforschungsbereich $950:$ « Les cultures du manuscrit en Asie, en Afrique et en Europe »
}

Université de Hambourg

Jean-Louis Georget

\section{OpenEdition}

\section{Journals}

Édition électronique

URL : http://journals.openedition.org/ifha/8028

DOI : $10.4000 /$ ifha. 8028

ISSN : 2198-8943

Éditeur

IFRA - Institut franco-allemand (sciences historiques et sociales)

Édition imprimée

Date de publication : 31 décembre 2014

ISSN : 2190-0078

Référence électronique

Jean-Louis Georget, «Le Sonderforschungsbereich 950 : " Les cultures du manuscrit en Asie, en

Afrique et en Europe » », Revue de l'IFHA [En ligne], 6 | 2014, mis en ligne le 31 décembre 2014,

consulté le 03 mai 2019. URL : http://journals.openedition.org/ifha/8028 ; DOI : 10.4000/ifha.8028

Ce document a été généré automatiquement le 3 mai 2019.

(CIFHA 


\title{
Le Sonderforschungsbereich 950 : « Les cultures du manuscrit en Asie, en Afrique et en Europe »
}

\author{
Université de Hambourg
}

Jean-Louis Georget

http://www.manuscript-cultures.uni-hamburg.de/About.html

Responsable : Michael Friedrich

1 Le groupe de recherche sur le manuscrit souligne combien ce dernier a été pendant des siècles le support de l'écrit avant d'être concurrencé de façon sérieuse au début de l'époque moderne par l'imprimerie.

2 En Occident, l'intérêt scientifique pour les manuscrits s'est accru dans les deux dernières décennies, encouragé en cela par l'apparition des médias électroniques et les questionnements qui s'en sont ensuivis au plan historique et systématique dans le domaine des sciences humaines et de la culture.

3 Parallèlement, on a retrouvé en Afrique et en Asie les manuscrits qui appartiennent à l'héritage culturel et on a commencé à archiver et à rendre accessible aux scientifiques cette masse d'environ 10 millions de pièces écrites.

4 Sur la base du projet 963 soutenu par la Deutsche Forschungsgemeinschaft et intitulé « Les cultures des manuscrits en Asie et en Afrique » (2008-2011), le projet de recherche part de l'artefact de matériel pour explorer la diversité empirique des cultures du manuscrit dans une perspective comparatiste et historique. Il établit un nouveau paradigme qui se distingue de la recherche menée jusqu'à aujourd'hui sur les manuscrits de manière disciplinaire et par aire régionale par le fait que d'une part il remet expressément en question la détermination culturelle de tout ce qui est présupposé en règle générale et qu'il souhaite d'autre part circonscrire des catégories et les caractéristiques universelles des cultures du manuscrit comme résultats possibles d'une recherche comparatiste.

5 La diversité des matières et disciplines concernées et la variété des cultures appréhendées permettent de surmonter des évidences non réfléchies (à la manière dont les évolutions 
contingentes européennes pourraient apparaître comme une régularité transposable à tous les continents) ou encore des dichotomies (Orient-Occident) telle qu'elles se sont produites en Europe, mais aussi en Asie et en Afrique. L'un des buts à long terme de cette recherche est d'établir une science du manuscrit comme recherche transdisciplinaire et de créer les outils utilisables durablement.

Le projet comporte plusieurs volets. La première partie est consacrée aux paratextes : elle s'attache aux formes de texte qui sont dans une relation de dépendance physique ou en termes de contenu vis-à-vis d'un texte principal. La relation entre paratexte et texte principal se caractérise par sa variabilité. Des éléments dépendants peuvent être intégrés au cours du temps comme sous-partie du texte principal. De la même façon, des éléments particuliers du texte principal peuvent devenir des paratextes. Le support qu'est le manuscrit, et notamment son mode de transmission par la copie favorise de telles séparations et de telles intégrations. Le projet promeut une recherche sur les conditions de tels changements en rapport avec les caractéristiques des cultures spécifiques du manuscrit.

7 Le second volet s'attache à l'organisation visuelle de manuscrits comme un champ tendu entre différentes disciplines qui doivent prendre en compte les constantes et les différences dans les cultures continentales des manuscrits. L'organisation visuelle d'un manuscrit peut être comprise comme son apparence et tous les facteurs qui la constituent, comme le format, la forme, la couleur, ou la disposition des signes. L'organisation visuelle concerne les formes des signes et la présentation individuelle des pages, mais également de l'architecture du manuscrit dans son ensemble. Si l'on comprend sous le terme de présentation la forme d'organisation de la page, et par conséquent de la surface, le regard porté sur l'architecture du manuscrit en fait un espace tridimensionnel dans laquelle chaque information occupe une place déterminée. L'organisation visuelle d'un manuscrit est également un ordonnancement du savoir, qui est dépendant de chacun des scripteurs, mais également des normes et des conventions qui permettent aux informations, malgré l'individualité et la singularité de chaque livre, d'être et de rester compréhensible et accessible. Elle informe sur les traditions de savoir et de réception de la connaissance.

8 Le troisième point concerne l'étude des différentes collections constituant la base de réflexion et le corpus du projet: présentation d'une collection de manuscrits bouddhiques de l'Est de l'Inde, étude des manuscrits et impressions de l'ancien tantra, collections de livres dans l'ancienne Chine ( $3^{\text {ème }}-^{1^{\text {er }}}$ siècle avant JC.), les manuscrits buyrik des Alévis, kurdes alaouites, les manuscrits de l'Ethiopie chrétienne depuis l'Antiquité tardive jusqu'au Moyen Age, le savoir philosophique et naturaliste des manuscrits grecs du cardinal Bessarion (1403-1472), la place des manuscrits en swahili dans les collections d'Afrique de l'Est.

9 L'ensemble de ces savoirs nourrit le travail d'un collège doctoral, accueillant également des étudiants boursiers du monde entier. Il permet aux doctorants de rédiger leur thèse dans un environnement structuré qui leur permet d'acquérir un savoir dans le domaine de la recherche sur les manuscrits au moyen d'ateliers spécialisés, mais également de cours magistraux dispensés de façon interdisciplinaire.

10 La quatrième partie du programme concerne la conservation et la mise à disposition des chercheurs et du public des connaissances ainsi acquises. Le répertoire de données sur les cultures des manuscrits doit permettre la protection et l'utilisation sur le long terme des donnes du projet. L'utilisation centrale du système MyCoRe évite l'éparpillement des 
données entre les différents projets. Le répertoire circonscrit les objets digitaux avec les métadonnées descriptives, construites en vertu des nécessités des différents sous-projets. Le répertoire permet une collaboration virtuelle entre les chercheurs et sert de plateforme virtuelle centrale pour les scientifiques concernés. Enfin, les termes de visualisation, d'analyse et de caractérisation désignent trois projets qui tentent d'expérimenter de nouvelles méthodes informatiques pour exploiter sans les endommager les sources que sont les manuscrits.

\section{AUTEUR}

JEAN-LOUIS GEORGET

(EHESS/IFHA) 